\title{
Nancy A. Heitzeg: The School-to-Prison Pipeline: Education, Discipline, and Racialized Double Standards
}

\author{
Praeger, Santa Barbara, CA, 2016, 123 pp, ISBN: 978-1-4408-3111-9
}

\author{
Mary Ellis ${ }^{1}$
}

Received: 14 June 2016/Accepted: 15 June 2016/Published online: 21 June 2016

(C) Springer International Publishing 2016

In Nancy Heitzeg's book, The School-to-Prison Pipeline: Education, Discipline, and Racialized Double Standards, she describes the hardships that African American adolescents endure through their schooling as they are discriminated and treated unfairly through discipline according to their race. Heitzeg introduces readers to the idea of the school-to-prison pipeline by providing research on what the pipeline is, how it was created, and how it continues to be an issue for adolescents. She goes on to explain the ways in which society impacts the pipeline and how certain aspects of the modern day schooling system further the discrimination of the pipeline. She also discusses the advantages that whites have over people of color because of the medical model of treatment. This treatment option is made most available to whites, as blacks are seen as criminal long before they commit crime and are therefore unable to be "rehabilitated". Finally Heitzeg discusses the ways in which the school-to-prison pipeline can be attenuated and the way that some good-intentioned programs cause much of the problems in schools. Education centers that seek to provide zero tolerance learning spaces and police presence in schools are indeed adding to the causes of the school-to-prison pipeline. In conclusion, Heitzeg offers an educational research outlet for readers to confront a major issue of juvenile justice, uncover the societal factors, and receive a call to action that challenges the programs we consider beneficial in schools.

Heitzeg provides a compelling argument in which she introduces the mechanics of a school-to-prison pipeline, delivers support that highlights society's influence in the

\footnotetext{
Mary Ellis

ellismar@indiana.edu

Indiana University, Bloomington, Bloomington, IN, USA
}

pipeline, and concludes with an educational opinion on a possible solution for ending the pipeline. In her introduction, Heitzeg outlines each of the three parts of her book and what will be discussed in each chapter. The beginning part of her book gives much introductory research as to what the school-to-prison pipeline actually looks like. She defines the pipeline in simple terms as the effect that schools have on adolescents' route out of schools and into prisons via racialized double standards. Hetizeg calls out the illegitimacy of the pipeline by noting that it is neither random or race neutral, but rather directly targets adolescents of color and those with disabilities. The pipeline emerges most predominantly in public schools that are under-funded and receive pressures from the government to perform better both on a social level and an academic level through the students. The pipeline serves to punish adolescents' wrongdoings with severe penalties that push them out of their schools and into prison and a life of crime. After an introductory two chapters, Heitzeg continues on to note the influence of social control on the rise of the school-to-prison pipeline. As society continues to deny the continued amount of racism, color-blind racism continues to be a contributing factor in many issues in the United States. Many people still stereotype people of color into categories of being more violent and more criminal. These thoughts and the media play an important role in the increase of the school-to-prison pipeline. In addition to these factors furthering the school-to-prison phenomenon, the more positive treatment that whites receive over people of color inhibits the pipeline from dissolving. Heitzeg discusses in part two of her book the implications that arise by the medical model. This model allows for more leniency for white offenders because they are given a rehabilitative approach as a punishment for crime, whereas people of color and with disabilities are pushed more towards 
automatic prison time. In the final part of her book, Heitzeg sets out to provide support for the most authentic way of ending the pipeline. The most important way to do so is to put an end to zero tolerance policies and police presence in schools. These two programs push for harsher punishments for adolescents who commit offenses in schools, which in turn leads them to the pipeline. Heitzeg finishes by introducing a call to action for her readers. She advocates for education not incarceration. Heitzeg strives to see schools become more about establishing a place where adolescents can make mistakes while gaining an education, rather than having their education ripped from them when they make a mistake. In conclusion, Hetizeg's book on the school-toprison pipeline introduces the readers to an atrocious phenomenon, gives information on society's impact on the growth of the pipeline, and finishes with a sense of optimism as she strives to see more education and less incarceration in America's schools.

Heitzeg takes the first chapter of her book to discuss the ramifications that the education system brings to the pipeline and how policies that were put in place to keep schools safer has instead allowed schools to conform to racial stereotypes, which places adolescents in the pipeline. One of the most disturbing occurrences in schools is the removal of boundaries between schools and the justice system. Schools have taken it upon themselves to hire law enforcement in their schools and enforce zero tolerance policies, which create a justice system within the schools that leads adolescents who break the rules to be on a narrow path to prison through the pipeline. Heitzeg expresses her dissatisfaction with school's zero tolerance policies and, while there is no official definition for such policies, she defines them as policies that encourage expulsion, suspension, and arrests being made in schools. These policies distort the distinction between disciplinary issues at school and breaking the law. This is just one way that zero tolerance policies add to the school-to-prison pipeline. These zero tolerance policies do not allow for a cushion period for adolescents who break school rules. Instead, adolescents who receive disciplinary violations are fast tracked to receive punishments from law enforcement officials who place them on the track to prison. These law enforcement officers are able to punish them so severely because more and more schools are adopting the SRO (school resource officer) program. This program originally began to increase safety in the days following the Columbine shooting. Heitzeg makes a note of an outside source saying that, in 1999, the U.S. Department of Justice "COPS in Schools" grant program noticeably increased the number of SROs in schools. On a more specific level, nearly one half of all public schools have assigned police officers. Because of the officer's presence in the school, the wrong actions of adolescents are being defined as criminal, even if it is only a mild offense. The officers are being relied on more and more to determine the fate of misguided teens and that fate is almost certainly one that puts an adolescent on the path to prison. In turn, these students who have broken the rules are given harsh punishments, and are then labeled as troublesome or disruptive. Once a child is labeled, they are unlikely to break that label but will instead adopt it as a part of them because the ability to get out from under the label is too hard. By enforcing zero tolerance policies and SROs in schools, the education system is not allowing adolescents to restart and learn from their mistakes. They are instead treating them as adults and giving them harsh punishments and placing them within a certain construct in which they cannot escape. While the education system negatively affects the school-to-prison pipeline, it doesn't equally affect all races. Heitzeg points out that students of color are suspended and expelled at more than three times the rate of whites in the same schools. In addition to African Americans being the most at risk in the pipeline, students with disabilities face disadvantages as well. Those with disabilities are often separated from the rest of students and are disciplined in ways that put them into the same confining constructs that surround students of color. Heitzeg points out that the students who are at the highest risk for dramatic disciplinary infractions in schools are "black students who have been labeled as having disabilities" (Heitzeg 2016, p. 14). While Heitzeg covers many topics in her first chapter, she ultimately conveys the atrocity of the school-to-prison pipeline and the negative effects that zero tolerance policies and SROs have on adolescents in the education system. These negative aspects primarily affect people of color, especially African Americans, and people living with disabilities. Hetizeg finishes with the thought that, because of the vastness of the issues dwelling within the pipeline, the solution will require a close examination of the social control in color blindness and the origination of the issue.

Heitzeg's second chapter discussed the ways in which segregated schools and educational funding are impacting the school-to-prison pipeline. She briefly touches on the segregation that appears in schools all across the United States and discusses the effect that Brown I and II had on racial segregation within the schools. She argues that, despite the efforts used through Brown II, racial segregation is still a common occurrence in schools. In addition to racial segregation, many schools see much segregation by class. In most middle class suburb schools, Whites and Asian Americans make up the majority of the student population, whereas African Americans and Latino/as are enrolled in high poverty areas. When compared to White and Asian American students, Black, Latino/as, and Indian American students have less educational opportunities, less experienced teachers and an easier curriculum rigor. As 
Heitzeg puts it, "in the era of double segregation, they face double-edged risk" (Heitzeg 2016, p. 21). After introducing the issues of double segregation in schools, Heitzeg goes on to discuss the negative ramifications of the No Child Left Behind (NCLB) act and its recent replacement, Every Student Succeeds Act (ESSA). NCLB emphasizes penalizing schools that do not do as well, many of the resources promised by NCLB never came through because of lack of funding, and has upped their stakes of performing well on tests. First, schools that are already underfunded get extra pressures from NCLB to perform at the top of their tier in standardized testing, yet they do not receive the funds to hire the best teachers, or get the best resources to perform well. Secondly, the NCLB does not come through on the funding promised. The funding provide by NCLB is less than $10 \%$ of most schools' budget. Most schools receive little funding from NCLB to help them provide better educations for adolescents, even though funding is what was originally promised by the NCLB act. Additionally, NCLB is continuing the problems of lack of funding by closing failing public schools and instead giving the money to charter schools, which hold no supported improvement in educational outcomes. Lastly, the NCLB has raised the stakes of performing poorly on tests, which has taken teaching away from the creative development of critical thinking skills. Essentially, NCLB puts an emphasis on teaching to the test, and this has reduced, instead of expanded, educational opportunities. Through these three major issues of the NCLB, and even now the ESSA, these acts play an important role in the school-to-prison pipeline through their use of pressures to perform. The schools that experience this pressure the most, highly segregated under-resourced urban schools, are the same schools that feed the pipeline. The NCLB, while on the outside seems to be created to improve schools, does little to actively educate adolescents. Another factor in education that feeds to the school-to-prison pipeline is the lack of qualified teachers to teach in non-segregated high poverty schools. Schools that administer to African American and Latino/as communities are the most likely to employ teachers who are new to teaching and have little experience. These teachers in turn are not equipped to deal with the cultural diversity that the school may bring. It is often argued that the best curriculum requires effective teacher training, an inclusive curriculum and broad commitment to multicultural competence. However teachers with this type of training do not exist and the ones that do have the experience needed, likely lack the cultural diversity knowledge they would need to perform effectively. Nearly $85 \%$ of K-12 teachers are white women (Heitzeg 2016, p. 27), and these teachers may have inadequate training and a lack of cultural knowledge to educate well adolescents in the higher poverty conditions. Lastly,
Heitzeg discourses that the government is more concerned with prisons and prison populations than with educating children at a younger age in order to keep them out of the prisons. Currently, prison populations are at an all-time high due to the War on Drugs. It was big news in the 1990's that California was the first state in which funding for prison building and correctional expenditures outpaced investment in education. However today, California is not the only state to make this mistake. The national average per capita for educating a child is $\$ 9500$ however is costs $\$ 43,000$ per year to keep a person incarcerated. States are seemingly more interested, more invested even, in incarceration than with educating adolescents. This fact pushes the school-to-prison pipeline out farther into the domain of the justice system. In a world where educating future criminals away from offending costs four times less than what it takes to incarcerate a person, states need to begin to take the cheaper and more effective option for decreasing prison overcrowding. In conclusion, schools feed the school-to-prison pipeline through double segregation, use of NCLB and its lack of resources, unequipped teachers, and more investments in prisons and incarcerations than in educating adolescents.

The third chapter of Heitzeg's book discussed primarily the effect that labeling theory posits happens to adolescents in schools. Labeling theory holds the idea that when their peers, parents, or other people in their life label adolescents as criminal, they adopt that label and become more criminal. Labeling theory explains the push that adolescents feel to commit to crime; it pushes adolescents on the school-to-prison pipeline. In explaining this phenomenon, Heitzeg discusses the idea of color-blind racism, which she defines as "the set of ideological devises used to explain contemporary racial inequality as the outcome of nonracial dynamics" (Heitzeg 2016, p. 40). This type of racism allows whites and other majorities to attribute the feelings of race as prejudice and brush it off as socially accepted. It is a way for whites to let themselves off the hook and not feel guilty for adopting racist beliefs in their everyday life. They fail to see themselves as privileged, so they instead attribute their color-blind racism to nonracial prejudices. Heitzeg also offers the idea that color-blind racism offers a code of terms that indirectly accuse people of color without ever mentioning race. In addition to people refusing to accept their racist beliefs, Heitzeg mentions the effects that color-blind racism has on the justice system. Citing The New Jim Crow, Heitzeg pulls into play the issues with the justice system labeling people of color in order to ease whites and others guilty consciences. The argument being made is that the criminal justice system now does the work that race used to do; the system labels people of color criminal and then treats them in ways that overtly racist systems rejected. Society deems it impermissible to 
discriminate based on race, so we do not. Instead we allow the justice system to take the hit by accepting labeling as a part of the system. Additionally, one of the most important manifestations of color-blind racism is done through the media, as Heitzeg outlines in the last parts of chapter three. She points out how the media uses the Criminal-BlackMan archetype to warp society's views of offenders. When the media reports stories on crime in society, a distinct difference can be noted in the types of reporting. When offenders are white, reporting tends to minimize the race of the offender and instead focus on trying to "humanize" the offender. Pictures shown of the offender are more likely to be everyday photos as opposed to mug shots and aspects of their life are used in an attempt to explain their behavior. However, when news coverage discusses black offenders, they almost always mention race and more often than not, mug shots are used when showing photographs of the offender. As Heitzeg eloquently writes, "youth of color are criminalized and their white peers medicalized for comparable behaviors..." (Heitzeg 2016, p. 39). Society deems white offenders as less morally responsible and is quicker to point to medical help as the solution or punishment for the crime, whereas blacks are almost always placed in prisons. The labeling theory and color-blind racism has a great effect on the pipeline, as it pushes children of color out onto the pipeline more. African American students and other students of color are expelled and suspended at rates much higher than their white peers. In fact, many teachers in schools fail to see their Black students as children at all. Heitzeg cites to research indicating that black boys are perceived as more responsible for their actions. They are often seen as much older than their peers of similar ages but different races. The implication of these techniques enhances the school-to-prison pipelines and moves adolescents into a life of criminality instead of educating them to keep them out of prisons. This tactic of labeling adolescents is one that strengthens the school-to-prison pipeline and does not allow for children to leave those hypotheses. In short, Heitzeg establishes what color-blind racism is and its effect supports by labeling theory. She outlines the effects that labeling has on children and how it pushes them into the pipeline and away from a life of unsegregated, non-discriminatory freedom.

In chapter four, Heitzeg touches on the recent influx of incarcerations due to imprisonment being the first choice for consequence, the effect the war on drugs has had on discrimination toward minority youth, and the rise in juveniles being treated as adults and thus having a record that follows them through the rest of their lives. Heitzeg begins detailing facts about the United States' recent rise in incarceration. Since 1970, the US has increased their prison populations ten-fold; in 1970, 200,000 were incarcerated, yet today 2.4 million are incarcerated. Heitzeg points out that this recent rise in prison population is not due to an increase in crime but is instead a result of imprisonment being a first response to social issues in the community. Within this era of mass incarceration, we find those being incarcerated racially discriminated against. Blacks are $13 \%$ of the total population, but $40 \%$ of all prisoners. As imprisonment is becoming the main response to some pressing social issues, blacks are taking the brunt of this force. Secondly, Heitzeg highlights how the War on Drugs has influenced the rise in imprisonment and the effect it has had on the pipeline. She returns to zero tolerance and how it again has negative effects, this time in relation to drug arrests. One of the key features of the War on Drugs is the idea of zero tolerance for any drug infractions. The mandatory sentencing for those caught for any drug infraction (possession, sale and manufacturing) has been the source for mass incarceration especially within Black and Latino communities. One specific standard changed the difference between infractions of crack cocaine versus powder cocaine. Five grams of crack, rather than 500 grams of powder cocaine, triggered a 5-year sentence. Yet, Backs and Latinos compromised $90 \%$ of the crack arrests but whites comprised $90 \%$ of arrests for powder cocaine. These specific laws, distinguishing a difference in types of drug arrests, are strictly racially discriminatory and positively affect the racial disparity in prisons. The War on Drugs has not allowed any leniency on offenders of drug laws, which thus prevents a person from accomplishing many things in adulthood. The War on Drugs, Heitzeg states, has become the primary source of both mass incarceration and racial disparity in the prison industrial complex. Heitzeg spends the most time in chapter four on juvenile injustice, the ways in which juveniles are being treated unfairly in prisons. One major way this happens is the recent increase in juveniles being tried in adult court. Twenty-three states have no lower age limit, which means that youth as young as eight may be charged, tried, and sentenced as adults. More and more states are beginning to allow children to be tried in an adult court in which they receive an adult punishment. In fact, the death penalty was only banned for juveniles in 2005. In addition to all youth's being targeted for adult court, African American and Latino youth are twice as likely as white youth to be referred to the adult criminal justice system. Lastly, this climate, which strengthens the punishments of juveniles, has compromised the confidentiality of their records. Juvenile records are now more easily accessible to schools, law enforcement, government agencies, and even media. Alongside harsher punishments, juveniles also have records, which may follow them far into adulthood, preventing them from accessing an education they desire or a lack of opportunities for housing and employment. The increase in imprisonment, the effect of the War on Drugs, 
and the confidentiality of juvenile, records have led to youth of color being set on the jailhouse track. Youth of color are targeted more because of the War on Drugs and the misconception that these minorities are more involved in gangs than their white peers. Youth of color are being persecuted from a young age, getting more adult sentences, and having long-lasting records that do not allow them to learn and change.

While Heitzeg focuses mostly on medicalization and criminalization in chapter five, she covers many important factors, taking special notes on the difference in schools' treatment of youth of color. First and foremost, the medical model offers an alternative to punishment of intentional law-breakers by offering treatment for mental illness. While this model seems appropriate for juvenile offenders, it is sadly not often used in that way in the justice system. Whites are far more likely to be exempt from punishment through the medical model. They instead receive treatment, as a way to ensure that they learn from their mistakes but do not have to receive harsh punishments for their wrongs. However, blacks are much more likely to receive some sort of punishment for their misgivings. Hetizeg notes that while blacks sometimes do receive a rehabilitative approach, it is often given in part with the rest of their legal sentences. However, their white counterparts receive medicalization as an alternative to criminalization. In addition, to youth of color not receiving equal treatment, they are also discriminatorily labeled in schools in comparison to their white counterparts. Within the context of the medical model, white and middle class students are diagnosed with disorders that are perceived to be less stigmatized and treatable, whereas the opposite happens for students of color. AHHD is one widely accepted illness especially in young children, and is more commonly identified by teachers when it occurs in white boys. Heitzeg says this idea "serves to divert disruptive white students from criminalizing penalties and offer them treatment instead" (Heitzeg 2016, p. 78). Students with ADHD are often not taken out of classrooms and are instead given special treatment to help them respond better with their peers. However, blacks are more often diagnosed with Oppositional Defiant Disorder (ODD), under the classification of a DSM-5 disability, meaning it is subject to psychiatric treatment. Blacks, in comparison to their white counterparts, are more likely to be diagnosed with DSM-5 disorders that overlap with the juvenile justice system, such as the more serious Conduct Disorder. In this way, black students are being more harshly labeled in schools and are more likely to receive punishment instead of treatment based on their disability. These students are also more likely to be treated harshly by the police. For students receiving special education services through Individuals with Disabilities Education Act (IDEA), one in every four
Black boys and two in every five Black girls experience suspension/expulsion. Over all, schools with high percentages of Black students, have the highest rates of suspension, expulsion, and arrest. The medical model was created to allow for rehabilitation of juvenile offenders but has instead provided another way for the government to racialize and discriminate against youth of color and forcing them onto the pipeline.

Part three of Hetizeg's book seeks to summarize her findings in chapter six, and propose solutions in chapter seven. Heitzeg spends much of chapter six highlighting the issues of zero tolerance policies and policing at school in a more in depth way than in chapter one. She points out that both zero tolerance policies and SROs in schools indicate that more students are at risk of being arrested at school, which leads to their being directly funneled into the legal system. Zero tolerance policies result in youth's being punished for behaviors that are not criminal, but are common misbehaviors in children of their age. For example, a Pennsylvania kindergartener tells her friends that she is going to shoot them with her Hello Kitty toy that makes soap bubbles. She is originally suspended for 2 days and the incident was reclassified as "a threat to harm others". The use of zero tolerance policies has enacted policies that are so strict they punish 5-year-old children for playing with their zero harm toys. These zero tolerance policies, which often end in children's being suspended or expelled, lead to many students dropping out, because of missing grades due to their suspension. Zero tolerance shows that out-of-school suspension can severely disrupt a student's academic progress in ways that have lasting negative consequences. Suspension and expulsion has been researched time and time again to have no real benefit for the child, socially, academically, or fundamentally in terms of learning the correct behavior. In addition to the negativity of zero tolerance policies, the use of SROs in schools raises the risk of severe racial discrimination for students from predominantly black, high poverty, communities. In suburban schools, students believe that cameras are present to enforce discipline within the schools and police officers are to protect from external forces. However, in urban schools that are majorly black, brown, and poor, students are perceived as the threat and target of use of force and arrest from SROs. Having police in schools leads to arrests, which then forces youth onto the pipeline leading them to prison and the adult criminal justice system. Through the use of zero tolerance policies and SROs, black students have begun to be targeted in their own schools. Black students, especially those with disabilities being supported by IDEA, are the most likely to face seclusion and physical restraint at school. This restraint and seclusion is responsible also for the push these youth feel toward the pipeline. Zero tolerance policies and SROs in schools lead youth to 
be more at risk for moving from school to prison through the use of suspension and expulsion. These principles lead to youth incarceration and incarceration leads to many problems later in life. Studies show that juvenile incarceration decreases chances of high school graduation by as much as $39 \%$ and increases the chances of incarceration as an adult by as much as $41 \%$. Zero tolerance policies and the use of SROs in schools damages juveniles more than support them and forces juvenile delinquents on the pipeline which leads them to a life in prison.

Heitzeg finishes her book with a call to action for her readers. She outlines what can be done to end the schoolto-prison pipeline and gives details for each level of responsibility. She offers solutions for the federal, state, and school district levels. On the federal level, she creates a three-principle tier for intervention. Principle one, climate and prevention, highlights, for example, prioritizing the use of evidence-based strategies to promote positive student behavior, collaborating with medical health professionals to develop age appropriate prevention and intervention strategies, and providing regular training and support to all school personnel on how to engage students and support positive behavior. Here Hetizeg's main concern is supporting positive behavior instead of punishing bad behavior. She makes it clear that the best way to encourage children to live their best lives is to provide positive reinforcement when things go right instead of negative punishment when things go awry. Principle two, expectations and consequences, involves families, students, and school personnel in the development of policies, creates policies that are developmentally appropriate and chooses removing students from classroom only as last resort. Here, Heitzeg stresses the importance of knowing what is best for each student group and creating policies that reflect their growth developmentally. Lastly, principle three, equity and continuous improvement, stresses the continuation of trained school personnel and gaining feedback from parents and families on punishment policies' effectiveness and how they are being received. On a state level, Heitzeg believes that it is up to the states to revise their own codes of conduct and implement policy changes. While zero tolerance policies have come under strict scrutiny lately, the use of SROs in schools remains a widely accepted request. However, states fail to look at evidence-based research that points to the negative aspects of SROs. Police presence in schools continues to grow, without mandated data collection, consistent training protocols, or consequences. States also have control over standards for school personnel and teachers, who play a significant role in the continuation of the school-to-prison pipeline. States must begin to take responsibility for their own actions, rewrite their code of conducts, and accept the current research on school policies in order to end the school-to-prison policy. Schools specifically can make a big difference in their students if they take upon some already adopted appropriate policies. Positive Behavioral Intervention and Supports (PBIS) has been adopted by 6000 schools and part of school-wide program. PBIS focuses on rewarding positive behavior among juveniles and attempts to diminish zero tolerance policies. Students exposed to PBIS have better educational outcomes and more pro-social behaviors and are subject to fewer disciplinary referrals. Another positive alternative to zero tolerance that needs to be adopted by more schools is restorative justice. Restorative Justice for Oakland Youth (RJOY), for example, rejects the usual search for blame and punishment and instead offers all parties a chance to mediate the conflict and repair harm. Restorative justice allows young students to begin to learn the benefits of confronting conflict in an attempt to restore relationships and learn to forgive. Lastly, some schools have begun to implement a transformative justice theory approach. This type of justice assumes that we must move forward rather than attempt to restore what was there before. Transformative justice looks to the future to see what needs to be changed in one's environment or social life to prevent future infractions. Much needs to be done to end the school-to-prison pipeline but if the nation works together on a federal, state, and individual school level, an end can be reached.

Overall, Heitzeg strives to show readers how the government is failing youth, especially youth of color in schools. Zero tolerance policies and SROs in schools do more damage and result in more juveniles becoming adult offenders. Heitzeg stresses that it is important to adopt strategies that are already working in schools, such as restorative and transformative justice policies. Ultimately, putting an end to the school-to-prison pipeline will not be easy, but if all people gain a better understanding of what needs to be done on their level of responsibility, progress can be achieved.

\section{Compliance with Ethical Standards}

Conflict of interest None.

\section{Reference}

Heitzeg, N. A. (2016). The school-to-prison pipeline: Education, discipline, and racialized double standards. Santa Barbara, CA: Praeger. 